\title{
Application of a Method for Engineering Multivalent Antibodies to Substantially Enhance Functional affinity of Clinical Trial Anti-SARS-CoV-2 Antibodies
}

\section{Adam Leach}

Institute of Cancer Research

Ami Miller

Institute of Cancer Research

Emma Bentley

National Institute for Biological Standards and Control

Giada Mattiuzzo

National Institute for Biological Standards and Control

Jemima Thomas

Institute of Cancer Research

Craig McAndrew

Institute of Cancer Research

Rob Montfort

Institute of Cancer Research

Terence Rabbitts ( $\nabla$ terry.rabbitts@icr.ac.uk)

Institute of Cancer Research

\section{Research Article}

Keywords: Avidity, antibody, valency, SARS-CoV-2, COVID-19, coronavirus, ELISA, spike antigen, tetramerization

Posted Date: March 10th, 2021

DOI: https://doi.org/10.21203/rs.3.rs-259484/v1

License: (c) (i) This work is licensed under a Creative Commons Attribution 4.0 International License.

Read Full License 


\title{
Application of a method for engineering multivalent antibodies to substantially enhance functional affinity of clinical trial anti-SARS-CoV-2 antibodies
}

\author{
Adam Leach ${ }^{1,+}$, Ami Miller ${ }^{1,+\$}$, Emma Bentley ${ }^{2}$, Giada Mattiuzzo ${ }^{2}$, Jemima Thomas ${ }^{1}$, \\ Craig McAndrew ${ }^{1}$, Rob Van Montfort ${ }^{1}$, Terence Rabbitts ${ }^{1}$ *
}

1 Institute of Cancer Research, Centre for Cancer Drug Discovery, Division of Cancer Therapeutics, 15 Cotswold Road, Sutton, London, SM2 5NG, UK

2 National Institute for Biological Standards and Control, Blanche Lane, South Mimms, Hertfordshire EN6 3QG, UK

+ Equal contributions authors

\$ current address: Evotec, 114 Innovation Dr, Milton Park, Abingdon, OX14 4RZ, UK

Key words: Avidity; antibody; valency; SARS-CoV-2; COVID-19; coronavirus; ELISA; spike antigen; tetramerization

Short title: Increasing functional affinity of anti-SARS-CoV-2 antibodies

\footnotetext{
${ }^{*}$ Corresponding author

Terry Rabbitts, Institute of Cancer Research, Centre for Cancer Drug Discovery, Division of Cancer Therapeutics, 15 Cotswold Road, Sutton, London, SM2 5NG, UK
} 
Email: terry.rabbitts@icr.ac.uk

- page 2 - 


\begin{abstract}
Infection by the severe acute respiratory syndrome coronavirus-2 (SARS-CoV-2) causes COVID-19 disease. Therapeutic antibodies are being developed that interact with the viral spike proteins to limit viral infection of epithelium. We have applied a method to dramatically improve the performance of anti-SARS-CoV-2 antibodies by enhancing avidity through multimerization using simple engineering to yield tetrameric antibodies. We have re-engineered six anti-SARS-CoV-2 antibodies using the human p53 tetramerization domain, including three clinical trials antibodies casirivimab, imdevimab and etesevimab. The method yields tetrameric antibodies, termed Quads, that retain efficient binding to the SARS-CoV-2 spike protein and show up to two orders of magnitude enhancement in neutralization of pseudovirus infection. The tetramerization method is simple and general and its application is a powerful methodological development for SARS-CoV-2 antibodies that are currently in pre-clinical and clinical investigation.
\end{abstract}




\section{Introduction}

There is a continued need for new antibodies for use in clinical situations such as acquired disease and infections. This requirement highlights the associated costs of both individual antibody development and production of sufficient antibody for each efficacious dose. In theory, higher potency antibodies require lower dose which reflects on the cost of goods for patient implementation. We recently described a method for increasing functional affinity through multivalent antibody engineering ${ }^{1}$ to significantly improve potency by avidity effects. We have now applied this methodology to enhancing anti- SARS-CoV-2 antibodies including two that are in clinical use for COVID-19.

The advent of new viruses that can infect humans is a continuing threat to the population. The emergence of SARS-CoV causing severe acute respiratory syndrome occurred in 2002 and followed in late 2019 by a novel coronavirus SARS-CoV-2 are examples ${ }^{2}$ \& PMID: 17934078 . Methodologies to produce the best antibodies are a critical need for keeping ahead of new, emerging infectious agents. Controlling the SARS-CoV-2 pandemic requires development of rapid, sensitive testing to determine transmission but also effective therapeutic antibodies to prevent viral entry into cells that causes the subsequent COVID-19 symptoms. SARS-CoV-2 enters cells by binding to the angiotensin-converting enzyme 2 (ACE2) receptor via a spike protein displayed on the viral coat surface ${ }^{3,4}$. The severity of the SARS-CoV-2 pandemic has initiated a major international effort to develop antibodies that bind to the SARS-CoV-2 spike protein in the ACE2 receptor binding domain (RBD). These have been derived as monoclonal antibodies (mAbs) from infected people ${ }^{5-12}$, by animal immunizations with SARS-CoV-2 spike glycoprotein ${ }^{13-17}$ or phage screening methods ${ }^{18-21}$. At present more than a dozen anti-SARS-CoV-2 mAbs are in clinical development ${ }^{22}$ of which bamlanivimab (LVCoV555, Lilly) and a cocktail antibody containing casirivimab (REGN10933, Regeneron) and imdevimab (REGN10987, Regeneron) have received Emergency Use Approval 
(EUA) from the Food and Drug Administration. Etesevimab (CB6/Junshi, also known as JS-016 and LY-CoV016) is in phase I trial (NCT04441931) and is also being trialled in combination with bamlanivimab (NCT04427501).

One of the aims of the anti-SARS-CoV-2 antibody work is the development of high affinity molecules that can bind to the RBD and prevent the virus from attaching to its cell receptor ACE2. This needs to be a rapid process as the pandemic is unabated and new variant SARS-CoV-2 viruses begin to appear ${ }^{23-27}$ that could potentially need a new generation of antibodies. Antibody development can be a laborious process involving affinity maturation to generate the highest affinity molecules with the most effective virus neutralization potency. Given the unprecedented manufacturing scale-up challenges that would be required to produce and rapidly treat millions of people, it is pertinent that the most effective antibodies are prioritized and developed whereby antibody dose per patient can be minimized without compromising efficacy. With this in mind, we adapted a new method ${ }^{1}$ for increasing valency of antibodies by fusing the human p53 tetramerization domain (TD) ${ }^{28}$. The multivalent antibodies created by this method are self-assembling multimeric proteins that can be engineered into various different formats (Supplementary Fig. 1). This simple method can be applied to any antibody and is currently especially pertinent to anti-SARS-CoV-2 antibodies. We have applied this method to six published anti-SARS-CoV-2 antibodies, two of which are currently in clinical use for COVID-19. We show that all the tetramerized antibodies have dramatically enhanced binding properties against SARS-CoV-2 spike protein. The simple multimerization strategy described in this study can be rapidly adapted to reformat other anti-SARS-CoV-2 antibodies or antibodies against any other targets. The enhanced anti-SARS-CoV-2 antibodies are now available for clinical development. 


\section{Results}

\section{A method for enhancement of anti-SARS-CoV-2 antibody potency by tetramerization}

A method for increasing valency of antibodies ${ }^{1}$ was employed to reformat published antiSARS-CoV-2 antibodies to increase the valency and augment functional affinity. The method is flexible because it simply relies on the p53 tetramerization domain to create self-multimerizing proteins. We have engineered various types of reformatted, engineered antibodies compared to IgG antibody as illustrated in Supplementary Fig. 1A). These include single chain variable fragment (scFv)-TD (Supplementary Fig. 1B), fragment antigen-binding (Fab)-TD (Supplementary Fig. 1C), whole immunoglobulin (Ig)-TD (Supplementary Fig. 1D) or whole Ig but lacking the hinge regions where disulphide bonding would normally occur (monomeric, mlg)-TD(Supplementary Fig. 1E).

We initially evaluated three anti-SARS-CoV-2 antibodies, viz. CR3022 isolated from a phage library ${ }^{8}$ and two mAbs obtained using data from a COVID-19 convalescent patient (H4 and B38) ${ }^{12}$ to evaluate the effect of multimerization on binding. We used CR3014 as a negative control as it binds SARS-CoV but not SARS-CoV-2 ${ }^{8}$. In these cases, the antibodies were prepared as tetramers with Fab (Fab-TD) or single chain variable fragment (scFv-TD) formats and the Quads purified to homogeneity by nickel chromatography and by size exclusion chromatography (SEC). The protein preparations were analyzed by SDS-PAGE to confirm the component chains (Fig. 1A, B).

In order to ensure maintained binding efficacy in the tetrameric forms, we evaluated the binding properties of the engineered antibodies by surface plasmon resonance (SPR) assays (Fig. 1C-I) with immobilized SARS-CoV-2 RBD protein. The original CR3022 lgG format (bivalent) and the engineered CR3022 Fab-TD (tetravalent) Quad have similar properties with $\mathrm{k}_{\text {off }}$ values at 0.00012 and $0.00042 \mathrm{~s}^{-1}$ respectively (Supplementary Table 1A). Further, the two COVID-19 patient-derived mAbs engineered 
as Fab-TD tetramers (H4 and B38, Fig. 1G, I) or as H4-scFv-TD (Fig. 1F) also maintained RBD binding and displayed slow off rates. The Fab versions (both CR3022 and H4) have more rapid off rate and subsequently a weaker Kd values (Fig. 1E, F). Comparing H4Fab-TD and H4-scFv-TD with H4-Fab illustrates the improved $\mathrm{k}_{\text {off }}$ and subsequently $\mathrm{K}_{d}$ values (Fig. 1F-H, Supplementary Table 1B) that results from the increase of valency. Notably, the H4-Fab-TD out-performs the H4-scFv-TD, presumably because the tetravalent Fab has additional avidity effects on binding to the RBD on the SPR chip. The $\mathrm{Kd}$ of Fab version of the $\mathrm{H} 4 \mathrm{mAb}(14 \mathrm{nM})$ is poor compared to the Quad proteins, mainly due to the relatively fast $k_{\text {off }}$ (Supplementary Table 1B). These data show that Quad proteins maintain and improve binding to the coronavirus spike protein after tetramerization. No binding to SARS-CoV-2 RBD was observed with the CR3014-Fab-TD Quad as expected ${ }^{8}$ (Supplementary Table 1A). Therefore, this method for tetramerization of the antibodies confers advantageous valency and avidity of binding to the SARS-CoV2 RBD protein.

\section{Augmented detection of SARS-CoV-2 spike protein using reformatted tetrameric antibodies}

We conducted direct enzyme-linked immunosorbent assays (ELISAs) to evaluate the effects of valency on the binding efficacy of the tetramerized Quad antibodies. We used spike protein-absorbed ELISA plates, with either SARS-CoV-2 S1 spike protein (Fig. 2A, comparing CR3022 formats and Fig. 2C comparing CR3022 with H4 and B38 Quads) or SARS-CoV-2 RBD (Fig. 2B, D with similar comparisons), and titrated antibody binding (detected by anti-HIS HRP antibody). CR3022-scFv or CR3022-Fab showed approximately $50 \%$ binding at about $1 \mathrm{nM}$ when interacting with either $\mathrm{S} 1$ or RBD, whereas whole IgG is closer to $0.1 \mathrm{nM}$ (Fig. 2A, B). The CR3022-Fab-TD or scFv-TD display the best functional affinity in this assay as the $50 \%$ binding of the tetramers CR3022-Fab-TD 
or scFv-TD was closer to $0.05 \mathrm{nM}$, due to increased valency and avidity effects of tetramerization.

The consequence of tetramerization was also tested with binding of the $\mathrm{H} 4$ and B38 mAbs, comparing interaction of H4-Fab-TD or H4-scFv-TD with CR3022-Fab-TD or CR3022-scFv-TD with the SARS-CoV-2 S1 spike protein (Fig. 2C) or the RBD (Fig. 2D). We observed the most potent Quad antibody was the H4-scFv-TD (50\% binding about $0.02 \mathrm{nM}$ ) which is about $5 \mathrm{x}$ better than CR3022 IgG, or compared with CR3022-scFv-TD ( $50 \%$ binding about $0.05 \mathrm{nM}$ ). The $\mathrm{H} 4$ or B38 Fab-TD proteins did not have especially potent binding curves as for instance H4-Fab-TD displayed $50 \%$ binding at about $0.1 \mathrm{nM}$, which parallels the whole IgG ELISA (Fig. 2A) and SPR (Fig. 1). B38-Fab-TD is the weakest of engineered proteins in its binding to the spike protein.

The increase in functional affinity in the reformatted H4 and CR3022 was emphasized by comparison of their scFv-TD forms with the H4-scFv or the CR3022-scFv and of Fab-TD with CR3022-Fab (respectively Supplementary Fig. 2A, B). The Quads saturate spike protein binding at lower molarity than the scFv or Fab counterparts. The antigenic epitopes on the SARS-CoV-2 spike protein for CR3022, H4 and B38 antibodies does not overlap ${ }^{12}$. It was possible therefore that the enhanced mAb tetramers could give additive effects for detection of the virus protein. This was assessed in ELISA binding of mixtures of CR3022 Fab-TD, B38-Fab-TD and H4-Fab-TD to SARS-CoV-2 RBD or S1 compared to CR3022-Fab-TD alone (respectively Supplementary Fig. 2C and D). We did not observe additive effects, probably because of steric hindrance of the bulky antibody tetramers binding to the spike protein antigens in proximity.

We further evaluated the potential of employing anti-SARS-CoV-2 CR3022 mAb in viral antigen detection systems. The spike protein detection levels were determined in a sandwich ELISA using, as capture proteins, a dimeric version of the extracellular domain of SARS-CoV-2 receptor ACE2-Fc ${ }^{29}$ (Supplementary Fig. 2E) or a tetrameric version 
(ACE2-Fc-TD) ${ }^{30}$ (Supplementary Fig. 2F). The CR3022 Fab-TD and scFv-TD tetramers displayed the highest signal performing with higher efficacy than the CR3022 IgG1 in various situations (Supplementary Fig. 2E-H). In all ELISA data, the non-binding CR3044 served as negative control, as predicted from published binding data ${ }^{8}$.

\section{Potency threshold increase in virus neutralization by tetrameric antibodies}

The H4 and B38 mAbs bind different epitopes on the spike protein and both are neutralizing ${ }^{12}$. The tetramer reformatted Quad versions of these were tested for their ability to interfere with coronavirus infection using a pseudotyped lentivirus-based neutralization assay. Interference with pseudotyped virus infection of HEK293T/17 cells stably expressing the ACE2 receptor and TMPRSS2 protease (HEK293T/17-A2-T2) by either H4-Fab-TD, H4-scFv-TD or B38-Fab-TD was compared to a commercially available neutralizing lgG mAb (SAD-S35) and to our tetramerized ACE2-Fc-TD protein ${ }^{30}$. The most effective protein in this neutralization assay was the tetrameric scFv version of $\mathrm{H} 4$ that interferes with a $50 \%$ inhibitory concentration $\left(\mathrm{IC}_{50}\right) 0.011 \mu \mathrm{g} / \mathrm{mL}$ compared to 0.23 $\mu \mathrm{g} / \mathrm{mL}$ for SAD-S35 and $0.051 \mu \mathrm{g} / \mathrm{mL}$ for ACE2-Fc-TD. The two Fab-TD antibodies have $\mathrm{IC}_{50}$ values of 0.15 (Fig. 3A). The $\mathrm{IC}_{50}$ of H4-scFv-TD and of ACE2-Fc-TD are closer when determined from molar amounts, being respectively $0.084 \mathrm{nM}$ and $0.113 \mathrm{nM}$ (Fig. 3B). These data show that the mAbs reformatted as Quad tetramers have greater potency for virus neutralization.

As a means to expand on the flexibility of the tetramer valency increase method, we investigated anti-SARS-CoV-2 antibodies for which clinical trials have been reported. There are several such anti-SARS-CoV-2 antibodies under clinical trial investigation either as mono-therapy, for instance, LY-CoV555 ${ }^{7}$ and CB6/Junshi, (etesevimab, also called LY-CoV016) are in phase I trials or as a cocktail REGN-COV2 which is a mixture of mAbs, 
REGN10987 (imdevimab) and REGN10933 (casirivimab) ${ }^{31}$. Accordingly, we reformatted the mAbs REGN10987, REGN10933 and CB6/Junshi with the p53 tetramerization domain into three types of Quad antibody format, namely Fab-TD, Ig-TD and mlg-TD (illustrated in Supplementary Fig. 1) to compare with the $\lg G$ antibody forms that are in the clinical trials.

These Quad proteins were purified using protein A or Ni-HTA chromatography and purity and integrity assessed with SDS-PAGE in reducing and non-reducing conditions (Supplementary Fig. 3A-C). To ensure that the Quad protein formats bind to the SARSCoV-2 RBD and to compare with the IgG forms, a plate-based surrogate neutralization assay measuring competitive binding of ACE2 with SARS-CoV-2 RBD was established (Supplementary Fig. 4). Anti-human IgG was used to capture ACE2-Fc and this was incubated with pre-mixed anti-SARS-CoV-2 competitor antibodies plus biotinylated SARSCoV-2 RBD. Non-competed RBD that bound to ACE2-Fc was detected with HRPconjugated streptavidin. In each case, we observed ACE2 binding neutralization was achieved at substantially lower concentrations of the tetramerized forms of mAb compared to the original IgG (Supplementary Fig. 4, panels A-C Fab-TD, panels D-F mlg and panels G-I Ig-TD). The fold potency change of the multimerized mAb versions was directly compared to the $\lg \mathrm{G}$ formats and calculated based on the $\mathrm{IC}_{50}$ values (Supplementary Fig. $4 \mathrm{~J}, \mathrm{~K})$. In this plate assay, the Fab-TD proteins were found to be consistently the most potent in neutralizing ACE2 interaction with SARS-CoV-2 RBD. The two larger molecular weight complexes of the Ig-TD and mlg-TD formats, yielded a similar fold enhancement of potency. Given all three Quad configurations are tetrameric molecules, it was interesting to observe that the size, shape and flexibility of these multimeric molecules appear to play an important role in potency modulation. Overall, the improvement trends in this platebased analysis consistently shows that all three anti-SARS-CoV-2 Quad formats have greatly improved potency over the clinical stage mAbs. 
The gold standard cell-based test for the efficacy of viral reagents is the capacity to neutralize the entry infection of viral particles into cells expressing the ACE2 receptor. We have used this approach to evaluate the H4 and B38 Quad proteins shown in Figure 3. Accordingly, we have determined the comparative efficiency that the Quad versions of the mAbs currently being evaluated in clinical trials to neutralize pseudotyped lentiviral infection into a permissive human cell line. Aligned to the plate competition assay, we compared the REGN10987, REGN10933 and CB6/Junshi IgG with Fab-TD, mlg-TD and Ig-TD formats. In addition, we compared these with the tetravalent $\mathrm{H} 4 \mathrm{mAb}$ in the form of an scFv tetrameric version (H4-scFv-TD) (Fig. 4). As a bench mark, Fig.4A displays the comparison of IgG proteins with the H4-scFv-TD showing that the two mAbs (REGN10987, REGN10933) and H4-scFv-TD have similar viral neutralization potencies. The CB6/Junshi mAb is the least potent (the calculated $\mathrm{IC}_{50}$ values are in Fig. $4 \mathrm{E}$ ). The relative neutralization potencies of the mAb IgG proteins are shown compared with the engineered tetramers, respectively Fab-TD (Fig.4B), mlg-TD (Fig.4C) and Ig-TD (Fig.4D) together with $\mathrm{IC}_{50}$ values and fold change in neutralization (Fig.4E).

In all three tetramer formats of the mAbs, there is improved $I_{50}$ compared to $\lg G$ in the neutralization of the pseudoviral infection and the potency trend in this assay is the Fab-TD, mlg-TD to Ig-TD. The Ig-TDs have the best $\mathrm{IC}_{50}$ enhancement being 59 (REGN10987), 13 (REGN10933) and 83 (CB6/Junshi) fold change compared to lgG mAbs (Fig.4D, E). The scFv-TD engineered version of the $\mathrm{H} 4 \mathrm{mAb}$ has an $\mathrm{IC}_{50}$ in the viral assay that approximates to those found for the Fab-TD and mlg-TD versions of the three clinical trial antibodies. Overall, we observed the greatest improvement for the CB6/Junshi tetramers and the greatest improved $I_{50}$ being in the CB6/Junshi Ig-TD (Fig. 4D). Interestingly, the Fab tetramers were the least potent in the viral assay (Fig. 4) compared to the plate-based competition assays (Supplementary Fig. 4). 


\section{Discussion}

\section{A simple protein engineering method to increase valency and avidity of anti-SARS-}

\section{CoV-2 antibodies}

We show that implementing the tetramerization method generates antibodies with dramatically enhanced binding and importantly significantly enhanced neutralization properties against SARS-CoV-2 spike protein. These super-charged multivalent antiSARS-CoV-2 mAbs are now available for further characterization and clinical investigation as the next-generation of anti-SARS-CoV-2 antibodies with superior binding and neutralization potency. This implies that lower dosage than currently used could be employed for therapeutic responses, which would be valuable for each treatment bolus but also for mass production as necessary amounts would be substantially lowered. Therefore, they have the potential to be developed as more effective treatment based on milligram scale doses as opposed to the gram-scale doses seen in the current EUA monoclonal antibody treatments ${ }^{7,31}$.

Our multivalent antibody method is a rapid technology that can boost antibody binding akin to affinity maturation. The method could easily be applied to other published anti-SARS-CoV-2 antibodies because it only needs inclusion of the p53 tetramerization domain. Further, the predicted structure of the $\lg -\mathrm{TD}$, as we also noted for our tetrameric ACE2 protein ${ }^{30}$, is analogous to the structure of $\lg \mathrm{A}$ antibodies which are tetrameric due to two $\lg \mathrm{A}$ monomers being linked by the $\mathrm{J}$ chain. This $\lg \mathrm{A}$ analogy may explain the potency enhancement in viral neutralization because potentially the Ig-TD can engage more than one viral particle, while the mlg-TD may be structurally constrained to function in the same way.

\section{Super-charging antibodies with enhanced neutralization potency through multimerization}


There is a remarkable increase in neutralization potency of the tetramerized formats with the Ig-TD versions having up to 80 -fold change in virus neutralization compared to the IgG1 mAbs. Generating high potency antibodies can be slow for a number of technical reasons and the requirement for rapid and flexible methods for enhancement is required. Several anti-SARS-CoV-2 antibodies have been developed that show extremely promising efficacy as COVID-19 therapeutic reagents ${ }^{11,31}$. Three of these have been subject to the tetramerization method within this study and in all three, substantial increased potency has been achieved. Thus, using this simple tetramerization method enhanced viral neutralization can be achieved due to increased valency and avidity.

It is remarkable that the Ig-TD format displays the greatest effective potency on the viral interference assays (Fig. 4) while the Fab-TD formats perform better in the in vitro competition assays (Supplementary Fig. 4). This difference may be influenced by size and flexibility of the Quad proteins but also due to the antigen availability in the two assays. In the plate assay, the ACE2 protein interactions with the SARS-CoV-2 spike RBD in a twodimensional system and the tetramer antibodies bind the SARS-CoV-2 RBD in solution. In the virus neutralization assays, the extended putative structure of the $\lg$-TD (like $\lg A$ ) could reach between virus particles extending the potency. It is also likely that steric hindrance effects may play distinct roles in the plate assay compared to the virus-based assay. Nonetheless, the choice of Quad format that appears to be more suitable for therapeutic development is the Ig-TD.

For potential clinical implementation, the Ig-TD that includes intact Fc regions, would have additional advantages, as it would be able to interact with Fc-receptors and invoke Fc-mediated effector function thus providing additional functionality. Further, the Fc would also be able to engage with neonatal Fc-receptor and could promote antibody recycling through rescue from normal lysosomal degradation and thus prolonged circulation half-life. 
Finally, the standard human IgG form of antibodies has a bivalent interaction with antigens. Increasing the valency of antibodies by tetramerization ${ }^{1}$ or by other multivalency methods ${ }^{18,32-34}$. This leads to higher functional affinity through valency and avidity effects 1,35. The implementation of our protein engineering method using the human p53 protein tetramerization domain is a simple and flexible method to increase valency ${ }^{1,30}$. Since community transmission is a major problem with SARS-CoV-2 and the appearance of new variants that appear to have increased transmissibility ${ }^{23,24,26,27}$ there is a need for effective rapid, sensitive testing. Employing the enhanced affinity tetrameric antibodies could be a valuable asset for lateral flow device development with reformatted antibodies that could produce enhanced signal and providing more sensitive reagents to be employed in lateral flow.

In conclusion, our results show that the method for tetramerization of antibodies points the way for the reformatting anti-SARS-CoV-2 antibodies to replace the existing versions for improved therapeutic applications (and possibly for viral antigen detection). The data further generalize the concept that mAbs reformatted as tetramers, using our flexible technology, will have greater potency. The technology can be applied to any antibody but also to all new forms of proteins, as we have shown for tetramerized ACE2 receptor for SARS-CoV-2 ${ }^{30}$. This will confer distinct advantages by invoking increased avidity for currently known viral targets, new viruses that may emerge in the future but also generally to any antigenic target. 


\section{Materials and Methods}

\section{Production and characterization of recombinant proteins}

Anti-SARS-CoV-2 antibodies, antibody fragments and ACE2 proteins were based on published data for these molecules ${ }^{30}$. Gene synthesis was used to generate clones for secretion and the human p53 tetramerization domain where appropriate for production of tetrameric Quads. All the sequences were cloned in pTT5 ${ }^{36}$ and expressed by secretion from Expi293F (Thermofisher) according to the manufacturer's recommendations. and the proteins were purified by nickel affinity chromatography and size exclusion as described ${ }^{30}$. SARS-CoV-2 viral spike protein and receptor binding protein was made as described elsewhere ${ }^{30}$ as Avi-tagged proteins and biotinylated using BirA enzyme ${ }^{37}$. All proteins were characterized by SDS-PAGE and by size exclusion chromatography.

Cloning, protein expression and purification of multivalent formats of anti-SARSCoV-2 clinical trial mAbs. Sequences of the Fab portion of the clinical stage mAbs REGN10987, REGN10933 ${ }^{31}$. and CB6/Junshi ${ }^{11}$. were reformatted into three different tetravalent types. Construction of the Fab-TD formats involved sub-cloning the p53 tetramerization domain (TD) linked onto the C-terminus of the immunoglobulin heavy chain $\mathrm{CH} 1$ domain devoid of the $\mathrm{CH} 2-\mathrm{CH} 3$ domains. For the lg-TD format, the TD domain was linked directly to the $\mathrm{C}$-terminus of the $\mathrm{CH} 3$ domain. The design of the monomeric IgTD (mlg-TD) format was identical to the Ig-TD format except the heavy chain core hinge region was removed. The corresponding light chains (LC) of the parental mAbs were kept intact. Expression constructs containing the modified heavy chains $(\mathrm{HC})$ together with the corresponding LC constructs were expressed in Expi293F cells using Expifectamine293 Reagent according to the manufacturer's recommendations (Thermo Fisher Scientific). Multimerized mAbs were purified directly from the culture supernatant by affinity purification. Fab-TD mAbs formats were purified using Ni-NTA and the Fc containing IgTD and mlg-TD mAbs formats were purified by Protein A affinity chromatography. All 
proteins were buffer exchanged and concentrated into PBS buffer using Amicon columns (Millipore) and aliquots were stored at $4^{\circ} \mathrm{C}$ or at $-80^{\circ} \mathrm{C}$ for long-term storage.

\section{Surface plasmon resonance of anti-SARS-Cov-2 antibodies with SARS-Cov-2 RBD}

SPR experiments were carried out using Biacore T100 (Cytiva, formerly GE Healthcare) in PBS buffer, pH 7.4 containing $0.05 \%$ Tween-20. A streptavidin-coated SA chip (Cytiva) was washed with $3 \times 30$ s injections of $1 \mathrm{M} \mathrm{NaCl} / 50 \mathrm{mM} \mathrm{NaOH}$ at $10 \mu \mathrm{L} / \mathrm{min}$ before biotinylated SARS-Cov-2 RBD $(0.2 \mu \mathrm{g} / \mathrm{mL})$ was captured to target immobilisation level 500RU. Antibody binding to SARS-Cov-2 RBD was analysed at $25^{\circ} \mathrm{C}$ using multi-cycle injections of antibody at six concentrations at $30 \mu \mathrm{L} / \mathrm{min}$ for $180 \mathrm{~s}$, followed by $420 \mathrm{~s}$ dissociation time. Concentrations between 0.312 - 10nM were used for CR3022 and CR3014 antibodies, while concentrations between $0.78-12.5 \mathrm{nM}$ were used for analysis of $\mathrm{H} 4$ and B38 antibodies. The surface was regenerated after each antibody injection using $1 \mathrm{M} \mathrm{NaCl} / 50 \mathrm{mM} \mathrm{NaOH}$ at $30 \mu \mathrm{L} / \mathrm{min}$ for 20 s contact time followed by $120 \mathrm{~s}$ stabilisation time. Flow cell 1 was used as a reference and so did not contain any captured SARS-Cov-2 RBD and was subtracted from all sensograms before analysis. Data were fitted to a 1:1 kinetics model using Biacore T200 Evaluation Software version 2.0.

\section{Direct ELISA methods}

ELISAs were carried out in clear, flat-bottomed 96-well MaxiSorp plates obtained from Thermo-Fisher Scientific,UK. SARS-CoV-2 protein (either spike or RBD) was prepared at $2 \mu \mathrm{g}$ per $\mathrm{mL}$ in PBS and $100 \mu \mathrm{L}$ per well added to an ELISA plate alongside negative control wells with $100 \mu \mathrm{L}$ PBS alone. Plates were then incubated for 16 hours at $4{ }^{\circ} \mathrm{C}$ and washed three times with $0.05 \%$ v/v Tween-20 in PBS (PBS-T) prior to addition of $150 \mu \mathrm{L}$ of $5 \% \mathrm{w} / \mathrm{v}$ BSA dissolved in PBS and room temperature (RT) incubation for 4 hours. Blocked wells were then washed 2 times with PBS-T, followed by the addition of $100 \mu \mathrm{L}$ of His-tagged antibody diluted in PBS-T and the plate incubated for 16 hours at $4{ }^{\circ} \mathrm{C}$. Wells 
were then washed 4 times with PBS-T and incubated with $100 \mu \mathrm{L}$ of anti-His-HRP (mouse monoclonal anti-polyhistidine antibody (clone HIS-1) conjugated to peroxidase (anti-HisHRP) was obtained from Sigma-Aldrich) diluted 1:4000 with $1 \% \mathrm{w} / \mathrm{v}$ BSA in PBS for 2 hours at RT, followed by washing 4 times with PBS-T. $25 \mu \mathrm{L}$ of TMB was added to each well, incubated for 20 minutes at $\mathrm{RT}$, then $25 \mu \mathrm{L} 3 \mathrm{M} \mathrm{HCl}$ added and absorbance read at $450 \lambda$.

\section{Sandwich ELISA methods}

ACE2-Fc or ACE2-Fc-TD was prepared at $3 \mu \mathrm{g}$ per $\mathrm{mL}$ in PBS and $100 \mu \mathrm{L}$ per well added to an ELISA plate alongside negative control wells with $100 \mu \mathrm{L}$ PBS alone. Plates were then incubated for 16 hours at $4{ }^{\circ} \mathrm{C}$ and washed three times with $0.05 \% \mathrm{v} / \mathrm{v}$ Tween-20 in PBS (PBS-T) prior to addition of $150 \mu \mathrm{L}$ of $5 \% \mathrm{w} / \mathrm{v}$ BSA dissolved in PBS and room temperature (RT) incubation for 4 hours. Blocked wells were then washed 2 times with PBS-T, $100 \mu \mathrm{L}$ of 0-300 nM RBD diluted in PBS-T added and the plate incubated for 16 hours at $4{ }^{\circ} \mathrm{C}$, before wells were again washed 4 times with PBS-T. His-tagged antibodies diluted to $1 \mathrm{nM}$ in PBS-T were then added and incubated for 3 hours at RT. Wells were then washed 4 times with PBS-T and incubated with $100 \mu \mathrm{L}$ of anti-His-HRP diluted 1:4000 with 1\% w/v BSA in PBS for 2 hours at RT, followed by washing 4 times with PBS-T. 25 $\mu \mathrm{L}$ of TMB was added to each well, incubated for 20 minutes at $\mathrm{RT}$, then $25 \mu \mathrm{L} 3 \mathrm{M} \mathrm{HCl}$ added and absorbance read at $450 \lambda$.

\section{Time course ELISA methods}

ACE2-Fc-TD was prepared at $3 \mu \mathrm{g}$ per $\mathrm{mL}$ in PBS and $100 \mu \mathrm{L}$ per well added to an ELISA plate alongside negative control wells with $100 \mu \mathrm{L}$ PBS alone. Plates were incubated for 16 hours at $4{ }^{\circ} \mathrm{C}$ and washed three times with $0.05 \%$ v/v Tween-20 in PBS (PBS-T) prior to addition of $150 \mu \mathrm{L}$ of $5 \% \mathrm{w} / \mathrm{v}$ BSA dissolved in PBS and room temperature (RT) incubation for 4 hours. Blocked wells were then washed 2 times with PBS-T, $100 \mu \mathrm{L}$ of 0- 
300 nM RBD diluted in PBS-T added and the plate incubated for 10 minutes or 1 hour at RT or $37^{\circ} \mathrm{C}$, before wells were washed 4 times with PBS-T. His-tagged CR3022-Fab-TD diluted to $1 \mathrm{nM}$ in PBS-T was added and the plate incubated for 10 minutes or 1 hour at RT or $37^{\circ} \mathrm{C}$, before wells were washed 4 times with PBS-T. $100 \mu \mathrm{L}$ of anti-His-HRP diluted $1: 4000$ with $1 \% \mathrm{w} / \mathrm{v}$ BSA in PBS was added and the plate incubated for 10 minutes or 1 hour at RT or $37^{\circ} \mathrm{C}$, before wells were washed 4 times with PBS-T. $25 \mu \mathrm{L}$ of TMB was added to each well, incubated for 15 minutes at RT, then $25 \mu \mathrm{L} 3 \mathrm{M} \mathrm{HCl}$ added and absorbance read at 450 $\lambda$. For simultaneous addition experiments, the SARS-CoV-2 RBD, CR3022-Fab-TD and anti-His-HRP antibody were added together.

\section{Competitive ELISA with tetravalent mAb formats.}

As a surrogate neutralization assay, inhibition of ACE2 interaction with SARS-CoV-2 RBD was measured using a competitive ELISA protocol. High binding 96-well plates (Corning) were coated overnight at $4^{\circ} \mathrm{C}$ with $100 \mathrm{ng}$ of anti-human IgG (Binding Site). Three washes were used between each subsequent step using PBS containing $0.1 \%$ Tween 20 and incubation at room temperature for 1 hour. Coated ELISA plates were blocked with $1 \%$ BSA followed by the addition of $100 \mathrm{ng}$ of human ACE2-Fc. A mixture containing serially diluted anti-SARS-CoV-2 multivalent mAbs starting at $30 \mathrm{nM}$ and a fixed amount of biotinylated SARS-CoV-2 RBD (75 pM) was pre-incubated at room temperature for 30 minutes prior to adding the mixture to the coated plate. Wells containing only the biotinylated RBD with no anti-SARS-CoV-2 antibody or wells containing ELISA assay buffer only ( $0.1 \%$ BSA) were used as control for calculating percentage neutralization. In the next step, HRP conjugated streptavidin (Abcam) diluted at 1 in 15,000 fold was added followed by $100 \mathrm{ul}$ of TMB to generate the signal. The reaction was stopped using $50 \mathrm{ul}$ of $1 \mathrm{M}$ sulphuric acid and the absorbance was measured at $450 \mathrm{~nm}$ using a CLARIOstar micro-plate reader (BMG Labtech). 


\section{SARS-CoV-2 lentiviral pseudotyped virus neutralization assay}

SARS-CoV-2 pseudotyped lentivirus was produced inHEK293T/17 cells following a similar approach as described ${ }^{38} \mathrm{DOI}: 10.6084 / \mathrm{m} 9$. figshare. $13502580^{39}$, a firefly luciferase reporter gene (pCSFLW) and the SARS-CoV-2 Spike gene (pCAGGS SARS-2-Spike) to produce virus containing supernatants. Neutralizing activity of antibodies was determined with 200 TCID50 of SARS-CoV-2 lentiviral pseudotyped virus using HEK293T/17 cells stably expressing ACE-2 and TMPRSS2 (HEK293T/17-A2-T2). These were plated at 20,000 cells/well in a 96-well plate for at least 2 hours at $37^{\circ} \mathrm{C}, 5 \% \mathrm{CO}_{2}$ before use. Mixtures of antibody and pseudotyped virus were incubated with target cells for 60 hours at $37^{\circ} \mathrm{C}, 5 \% \mathrm{CO}_{2}$ and infection determined by luciferase expression using the Promega Bright-Glo assay system and GloMax Navigator plate reader, following manufacturer's instructions. Data are normalized to pseudotyped virus and cell only controls and nonlinear regression analysis performed within GraphPad Prism, for $\mathrm{IC}_{50}$ values. 


\section{References}

1. Miller, A., S. Carr, T. Rabbitts, and H. Ali, Multimeric antibodies with increased valency surpassing functional affinity and potency thresholds using novel formats. MAbs, 2020. 12: 1752529.

2. Dhama, K., S.K. Patel, K. Sharun, M. Pathak, R. Tiwari, M.I. Yatoo, Y.S. Malik, R. Sah, A.A. Rabaan, P.K. Panwar, K.P. Singh, I. Michalak, W. Chaicumpa, D.F. Martinez-Pulgarin, D.K. Bonilla-Aldana, and A.J. Rodriguez-Morales, SARS-CoV2 jumping the species barrier: Zoonotic lessons from SARS, MERS and recent advances to combat this pandemic virus. Travel Med Infect Dis, 2020. 37: 101830.

3. Kuba, K., et al., A crucial role of angiotensin converting enzyme 2 (ACE2) in SARS coronavirus-induced lung injury. Nat Med, 2005. 11: 875-9.

4. Hoffmann, M., H. Kleine-Weber, S. Schroeder, N. Kruger, T. Herrler, S. Erichsen, T.S. Schiergens, G. Herrler, N.H. Wu, A. Nitsche, M.A. Muller, C. Drosten, and S. Pohlmann, SARS-CoV-2 Cell Entry Depends on ACE2 and TMPRSS2 and Is Blocked by a Clinically Proven Protease Inhibitor. Cell, 2020. 181: 271-280 e8.

5. Brouwer, P.J.M., et al., Potent neutralizing antibodies from COVID-19 patients define multiple targets of vulnerability. Science, 2020. 369: 643-650.

6. Cao, Y., et al., Potent Neutralizing Antibodies against SARS-CoV-2 Identified by High-Throughput Single-Cell Sequencing of Convalescent Patients' B Cells. Cell, 2020. 182: 73-84 e16.

7. Chen, P., et al., SARS-CoV-2 Neutralizing Antibody LY-CoV555 in Outpatients with Covid-19. N Engl J Med, 2020.

8. ter Meulen, J., E.N. van den Brink, L.L. Poon, W.E. Marissen, C.S. Leung, F. Cox, C.Y. Cheung, A.Q. Bakker, J.A. Bogaards, E. van Deventer, W. Preiser, H.W. Doerr, V.T. Chow, J. de Kruif, J.S. Peiris, and J. Goudsmit, Human monoclonal 
antibody combination against SARS coronavirus: synergy and coverage of escape mutants. PLoS Med, 2006. 3: e237.

9. Rogers, T.F., et al., Isolation of potent SARS-CoV-2 neutralizing antibodies and protection from disease in a small animal model. Science, 2020. 369: 956-963.

10. Seydoux, E., et al., Analysis of a SARS-CoV-2-Infected Individual Reveals Development of Potent Neutralizing Antibodies with Limited Somatic Mutation. Immunity, 2020. 53: 98-105 e5.

11. Shi, R., et al., A human neutralizing antibody targets the receptor-binding site of SARS-CoV-2. Nature, 2020. 584: 120-124.

12. Wu, Y., et al., A noncompeting pair of human neutralizing antibodies block COVID19 virus binding to its receptor ACE2. Science, 2020. 368: 1274-1278.

13. Esparza, T.J., N.P. Martin, G.P. Anderson, E.R. Goldman, and D.L. Brody, High affinity nanobodies block SARS-CoV-2 spike receptor binding domain interaction with human angiotensin converting enzyme. Sci Rep, 2020. 10: 22370.

14. Hansen, J., et al., Studies in humanized mice and convalescent humans yield a SARS-CoV-2 antibody cocktail. Science, 2020. 369: 1010-1014.

15. Huo, J., et al., Neutralizing nanobodies bind SARS-CoV-2 spike RBD and block interaction with ACE2. Nat Struct Mol Biol, 2020. 27: 846-854.

16. Wrapp, D., D. De Vlieger, K.S. Corbett, G.M. Torres, N. Wang, W. Van Breedam, K. Roose, L. van Schie, V.-C.C.-R. Team, M. Hoffmann, S. Pohlmann, B.S. Graham, N. Callewaert, B. Schepens, X. Saelens, and J.S. McLellan, Structural Basis for Potent Neutralization of Betacoronaviruses by Single-Domain Camelid Antibodies. Cell, 2020. 181: 1004-1015 e15.

17. Xiang, Y., S. Nambulli, Z. Xiao, H. Liu, Z. Sang, W.P. Duprex, D. SchneidmanDuhovny, C. Zhang, and Y. Shi, Versatile and multivalent nanobodies efficiently neutralize SARS-CoV-2. Science, 2020. 370: 1479-1484. 
18. Bracken, C.J., S.A. Lim, P. Solomon, N.J. Rettko, D.P. Nguyen, B.S. Zha, K. Schaefer, J.R. Byrnes, J. Zhou, I. Lui, J. Liu, K. Pance, Q.S.B. Consortium, X.X. Zhou, K.K. Leung, and J.A. Wells, Bi-paratopic and multivalent VH domains block ACE2 binding and neutralize SARS-CoV-2. Nat Chem Biol, 2021. 17: 113-121.

19. Custodio, T.F., H. Das, D.J. Sheward, L. Hanke, S. Pazicky, J. Pieprzyk, M. Sorgenfrei, M.A. Schroer, A.Y. Gruzinov, C.M. Jeffries, M.A. Graewert, D.I. Svergun, N. Dobrev, K. Remans, M.A. Seeger, G.M. Mclnerney, B. Murrell, B.M. Hallberg, and C. Low, Selection, biophysical and structural analysis of synthetic nanobodies that effectively neutralize SARS-CoV-2. Nat Commun, 2020. 11: 5588.

20. Li, W., et al., High Potency of a Bivalent Human VH Domain in SARS-CoV-2 Animal Models. Cell, 2020. 183: 429-441 e16.

21. Schoof, M., et al., An ultrapotent synthetic nanobody neutralizes SARS-CoV-2 by stabilizing inactive Spike. Science, 2020. 370: 1473-1479.

22. DeFrancesco, L., COVID-19 antibodies on trial. Nat Biotechnol, 2020. 38: 12421252.

23. Greaney, A.J., et al., Complete mapping of mutations to the SARS-CoV-2 spike receptor-binding domain that escape antibody recognition. bioRxiv, 2020.

24. Hodcroft, E.B., M. Zuber, S. Nadeau, K.H.D. Crawford, J.D. Bloom, D. Veesler, T.G. Vaughan, I. Comas, F.G. Candelas, T. Stadler, and R.A. Neher, Emergence and spread of a SARS-CoV-2 variant through Europe in the summer of 2020. medRxiv, 2020.

25. Kemp, S.A., et al., Neutralising antibodies in Spike mediated SARS-CoV-2 adaptation. medRxiv, 2020.

26. Korber, B., et al., Tracking Changes in SARS-CoV-2 Spike: Evidence that D614G Increases Infectivity of the COVID-19 Virus. Cell, 2020. 182: 812-827 e19. 
27. Popa, A., et al., Genomic epidemiology of superspreading events in Austria reveals mutational dynamics and transmission properties of SARS-CoV-2. Sci Transl Med, 2020. 12.

28. Melero, R., S. Rajagopalan, M. Lazaro, A.C. Joerger, T. Brandt, D.B. Veprintsev, G. Lasso, D. Gil, S.H. Scheres, J.M. Carazo, A.R. Fersht, and M. Valle, Electron microscopy studies on the quaternary structure of p53 reveal different binding modes for p53 tetramers in complex with DNA. Proc Natl Acad Sci U S A, 2011. 108: 557-62.

29. Lei, C., K. Qian, T. Li, S. Zhang, W. Fu, M. Ding, and S. Hu, Neutralization of SARS-CoV-2 spike pseudotyped virus by recombinant ACE2-Ig. Nat Commun, 2020. 11: 2070.

30. Miller, A., A. Leach, J. Thomas, C. McAndrew, E. Bentley, G. Mattiuzzo, L. John, A. Mirazimi, G. Harris, N. Gamage, S. Carr, H. Ali, R.L. van Montfort, and T.H. Rabbitts, A super-potent tetramerized ACE2 protein displays enhanced neutralization of SARS-CoV-2 virus infection. Submitted for publication, 2021.

31. Weinreich, D.M., et al., REGN-COV2, a Neutralizing Antibody Cocktail, in Outpatients with Covid-19. N Engl J Med, 2020.

32. Fan, C.Y., C.C. Huang, W.C. Chiu, C.C. Lai, G.G. Liou, H.C. Li, and M.Y. Chou, Production of multivalent protein binders using a self-trimerizing collagen-like peptide scaffold. FASEB J, 2008. 22: 3795-804.

33. Liu, M., X. Wang, C. Yin, Z. Zhang, Q. Lin, Y. Zhen, and H. Huang, Targeting TNFalpha with a tetravalent mini-antibody TNF-TeAb. Biochem J, 2007. 406: 237-46.

34. Zhu, X., L. Wang, R. Liu, B. Flutter, S. Li, J. Ding, H. Tao, C. Liu, M. Sun, and B. Gao, COMBODY: one-domain antibody multimer with improved avidity. Immunol Cell Biol, 2010. 88: 667-75. 
35. Liu, H., N.C. Wu, M. Yuan, S. Bangaru, J.L. Torres, T.G. Caniels, J. van Schooten, X. Zhu, C.D. Lee, P.J.M. Brouwer, M.J. van Gils, R.W. Sanders, A.B. Ward, and I.A. Wilson, Cross-Neutralization of a SARS-CoV-2 Antibody to a Functionally Conserved Site Is Mediated by Avidity. Immunity, 2020. 53: 1272-1280 e5.

36. Durocher, Y., S. Perret, and A. Kamen, High-level and high-throughput recombinant protein production by transient transfection of suspension-growing human 293-EBNA1 cells. Nucleic Acids Res, 2002. 30: E9.

37. Fairhead, M. and M. Howarth, Site-specific biotinylation of purified proteins using BirA. Methods Mol Biol, 2015. 1266: 171-84.

38. Carnell, G., K. Grehan, F. Ferrera, E. Molesti, and N. Temperton, An optimized method for the production using PEI, tritration and neutralization of SARS-CoV spike luciferase pseudotypes. Bio-protocol, 2017. 7: e2514.

39. Zufferey, R., D. Nagy, R.J. Mandel, L. Naldini, and D. Trono, Multiply attenuated lentiviral vector achieves efficient gene delivery in vivo. Nat Biotechnol, 1997. 15: $871-5$ 


\section{Acknowledgements}

$\mathrm{AM}, \mathrm{AL}$ and THR were funded by the Institute of Cancer Research and RvM team is supported by Cancer Research UK funding grant code: C2739/A2289. We are indebted to Dr. Chris Lindley and MacVector Inc. for very generously providing a license for their DNA handling software MacVector that greatly assisted the development of this work. We also thank Dr Peter Cherepanov from the Crick Institute for providing a sample of SARScov-2 S1 spike protein. The clinical stage antibody and Quad constructs for generating tetrameric versions of REGN10987, REGN10933 and CB6 were designed and produced by Quadrucept.

\section{Author's contributions}

Participated in research concept and design: THR

Conducted experiments: AL, AM, EB, JT, CM

Performed data analysis: All authors

Wrote or contributed to the writing of the manuscript: All authors

\section{Conflict of interest statement}

Terence Rabbitts is a stake holder in Quadrucept Ltd. None of the other authors have any conflicts of interest to declare.

Additional information: Supplementary Information accompanies this paper. 
A.

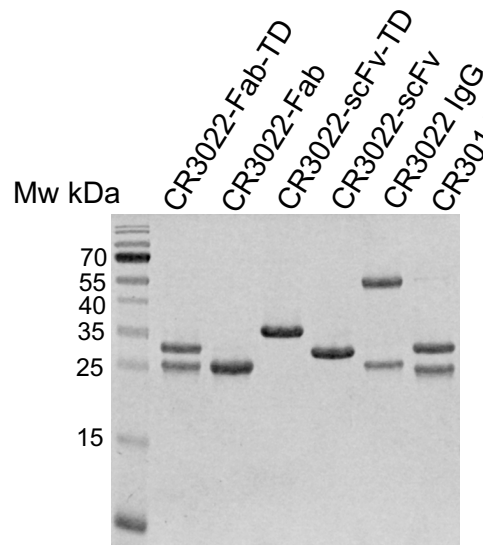

C.

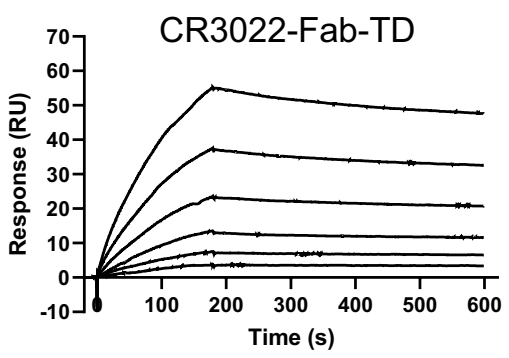

E.

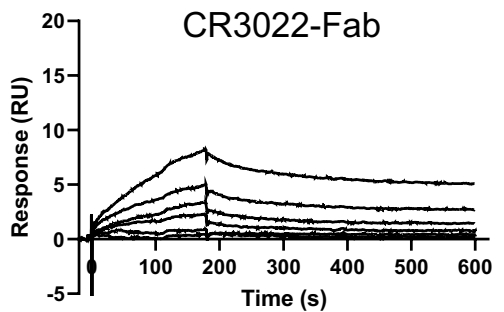

G.

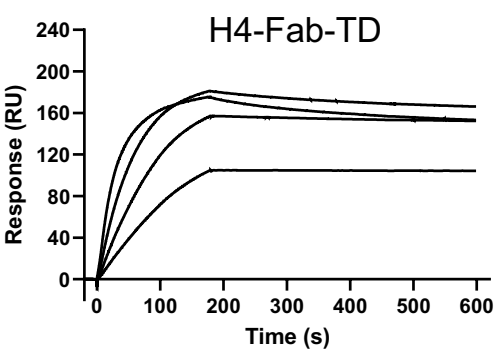

I.

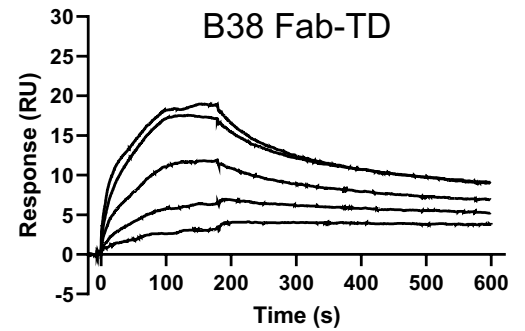

B.

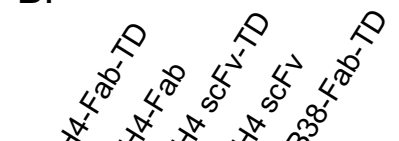

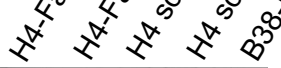

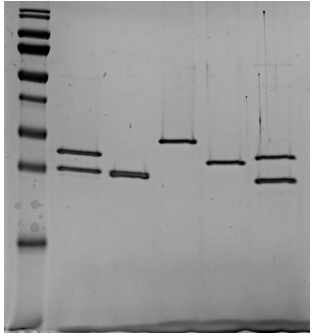

D.

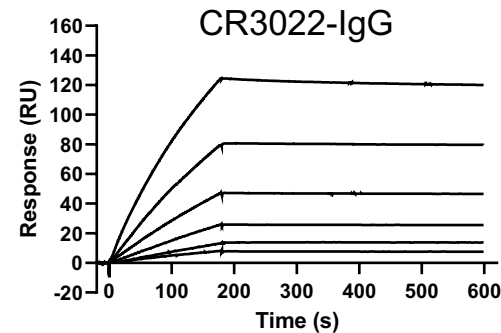

F.

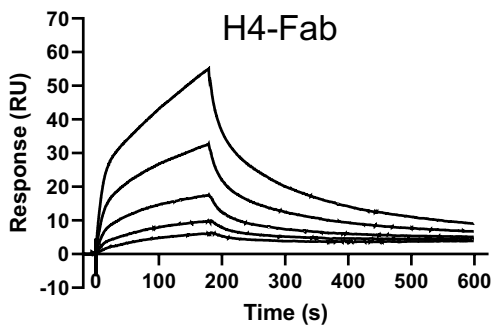

$\mathrm{H}$.

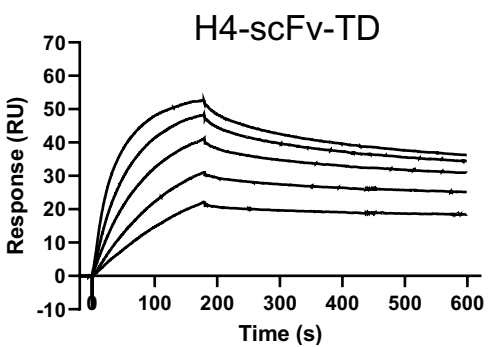

Figure 1. Characterization of anti-SARS-Cov-2 antibodies with different valencies by surface plasmon resonance 
The binding potencies of the anti-SARS-Cov-2 tetrameric Quad proteins was determined using surface plasmon resonance. Purified proteins were captured using immobilized SARS-Cov-2 RBD, carried out with a Biacore T200 instrument.

(A) Anti-SARS-Cov-2 antibodies were expressed by transfection and secretion from Expi293 suspension cells and characterized by SDS-PAGE following purification by Niaffinity chromatography and gel filtration. Gels were stained with InstantBlue Ultrafast Protein Stain and Mw size markers included (left hand lanes).

(C-I) Antibody binding to SARS-Cov-2 RBD was evaluated using SPR. Biotinylated SARSCoV-2 RBD was captured on a streptavidin chip and antibodies flowed over the surface at different concentrations. CR3022 and CR3014 antibody concentrations were 10, 5, 2.5, 1.25, 0.625 and $0.312 \mathrm{nM}$, while those for $\mathrm{H} 4$ and $\mathrm{B} 38$ antibodies were 12.5, 6.25, 3.125, 1.56 and $0.78 \mathrm{nM}$. Sensograms representative of two independent experiments are shown for (C) CR3022-Fab-TD, (D) CR3022-IgG, (E) CR3022-Fab, (F) H4-Fab (G) H4-Fab-TD (H) H4-scFv-TD and (I) B38-Fab-TD. Kinetic parameters are shown in Supplementary Table S1. Tetramerization decreases dissociation rates for the multimeric species compared to the monomeric proteins. This results in increased affinity for SARS-Cov-2 RBD for CR3022-Fab-TD compared to CR3022-Fab, and for H4-Fab-TD and H4-scFv-TD compared to H4-Fab. 
A.

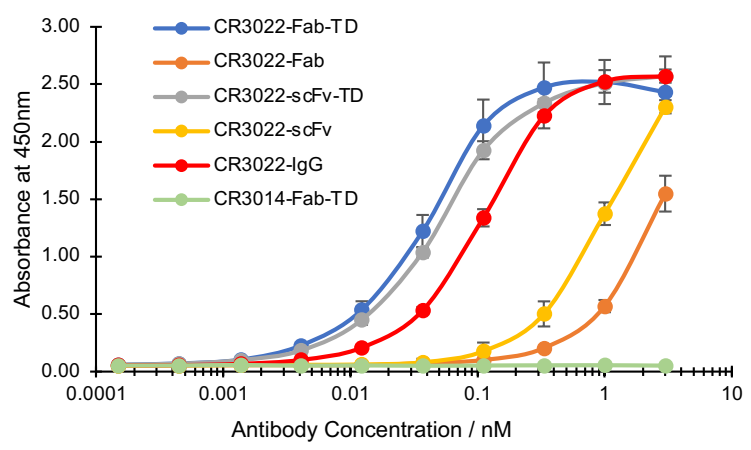

C.

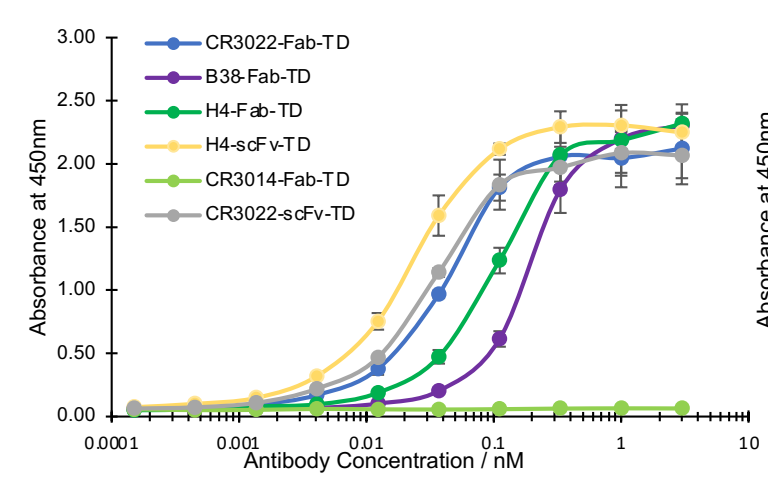

B.
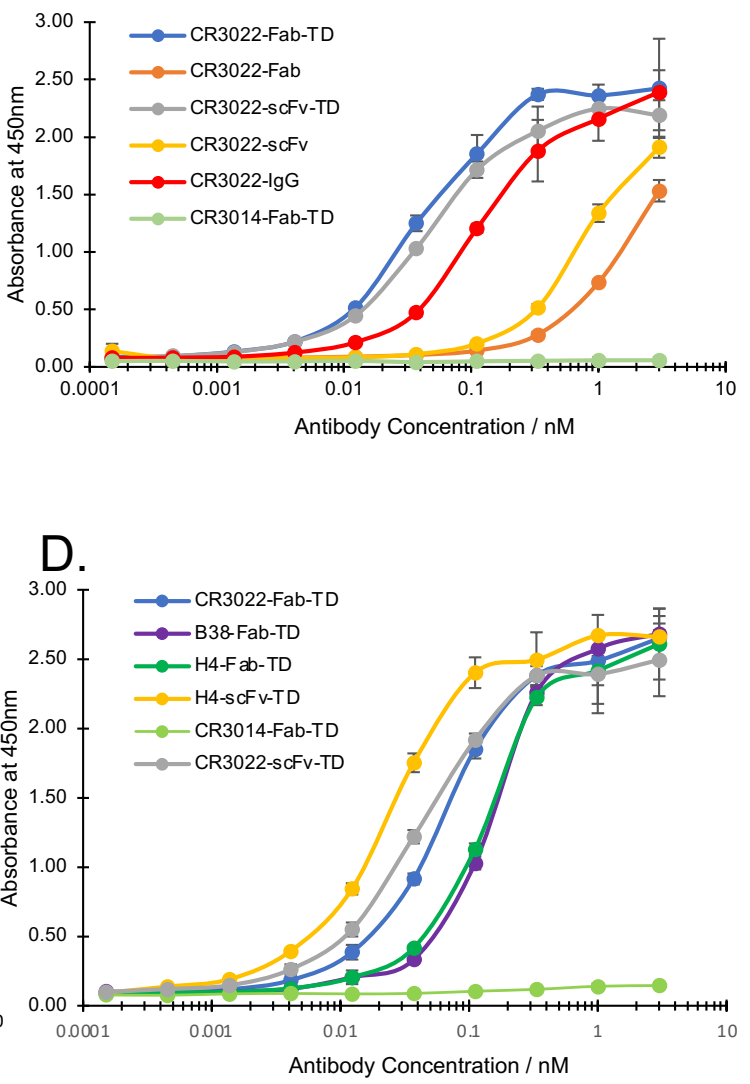

Figure 2. Direct ELISA immunoassays with anti-SARS-CoV-2 antibodies detecting viral spike proteins

The ability and potency of engineered anti-SARS-CoV-2 antibodies to bind to the viral spike proteins was compared using Enzyme-linked immunosorbent assays (ELISAs). SARS-CoV-2 spike protein as either S1 (panel A and C) or RBD (panel B and D) was adsorbed onto immunoassay plates at $2 \mu \mathrm{g}$ per $\mu \mathrm{L}$ for 16 hours at $4{ }^{\circ} \mathrm{C}$. Wells were thoroughly washed, blocked, and various concentrations of the indicated His-tagged antibodies were added to each well and incubated for 16 hours at $4^{\circ} \mathrm{C}$, followed by washing and incubation with anti-His-HRP antibody for 2 hours at room temperature. Colour was developed using TMB and absorbance read at $450 \lambda$. All samples were run in triplicate. 

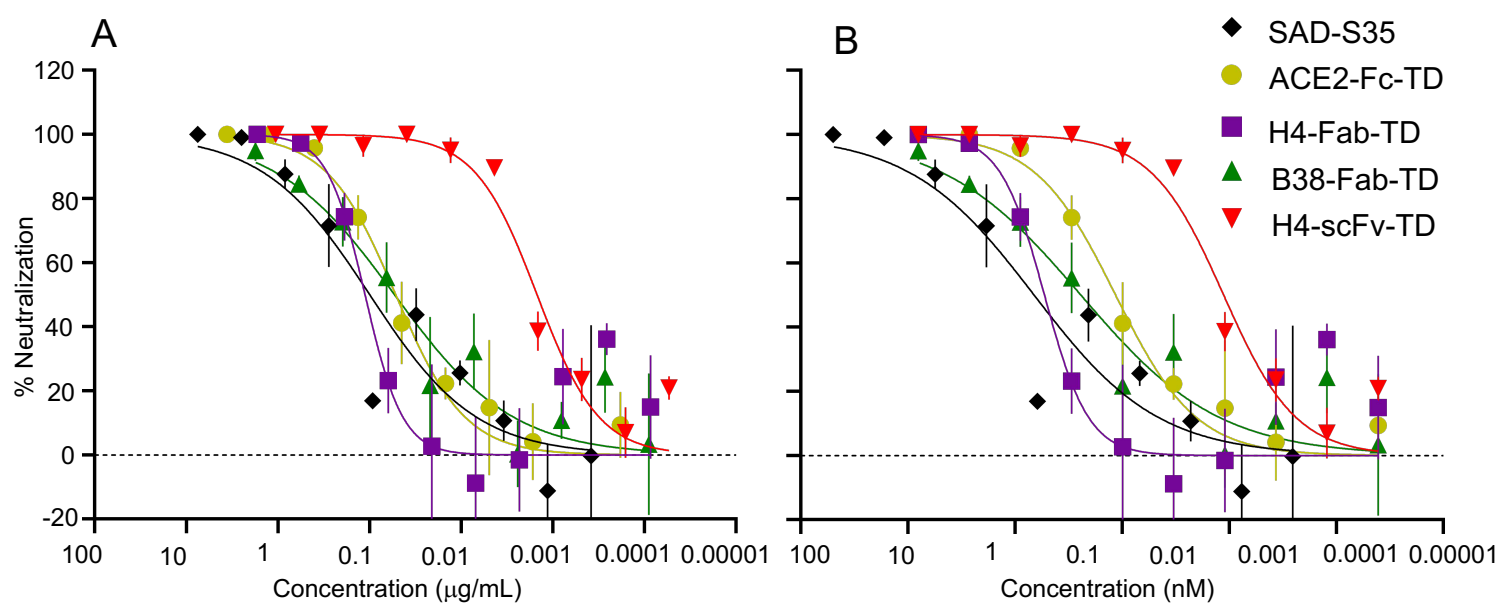

\begin{tabular}{|l|l|}
\hline Anti-CoV-2 protein & $\mathrm{IC}_{50}(\mathrm{ng} / \mathrm{mL})$ \\
\hline SAD-S35 & 0.099 \\
\hline ACE2-Fc-TD & 0.052 \\
\hline B38-Fab-TD & 0.112 \\
\hline H4-Fab-TD & 0.053 \\
\hline H4-scFv-TD & 0.001 \\
\hline
\end{tabular}

\begin{tabular}{|l|l|}
\hline Anti-CoV-2 protein & IC $_{50}(\mathbf{n M})$ \\
\hline SAD-S35 & 0.663 \\
\hline ACE2-Fc-TD & 0.115 \\
\hline B38-Fab-TD & 0.531 \\
\hline H4-Fab-TD & 0.243 \\
\hline H4-scFv-TD & 0.011 \\
\hline
\end{tabular}

Figure 3. Tetramerized $\mathrm{H} 4$ and B38 anti-SARS-CoV-2 antibodies are potent inhibitors of virus infection

The viral infection neutralizing potency of tetrameric versions of the mAbs $\mathrm{H} 4$ and B38 was examined in SARS-CoV-2 pseudovirus infection assays. Increasing concentrations of H4-scFv-TD, H4-Fab-TD or B38-Fab-TD were incubated with HEK 293T/17-A2-T2 cells after 1 hour. The cells were incubated for 60 hours before luciferase activity, indicative of viral entry, was determined. The efficacy was compared to the neutralization effects of a commercial anti-SARS-CoV-2 mAb SAD-S35 (AcroBiosystems) and a tetramerized ACE2-Fc-TD. Data are represented in $\mu \mathrm{g} / \mathrm{mL}$ (panel A) and $\mathrm{nM}$ (panel B). Calculated $\mathrm{IC}_{50}$ values are tabulated below each set of curves. The assays were performed twice, in duplicate with error bars indicating the standard error. 


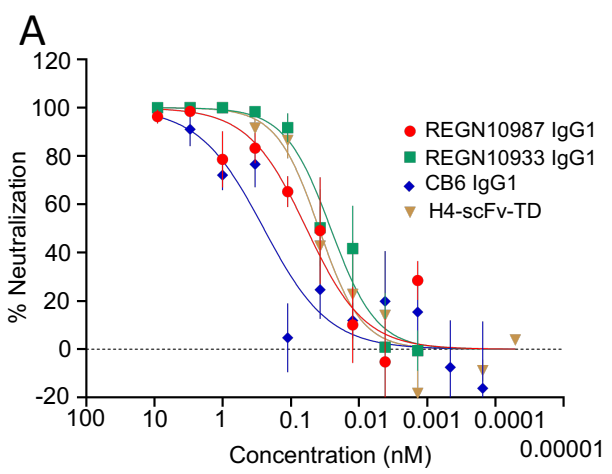

C

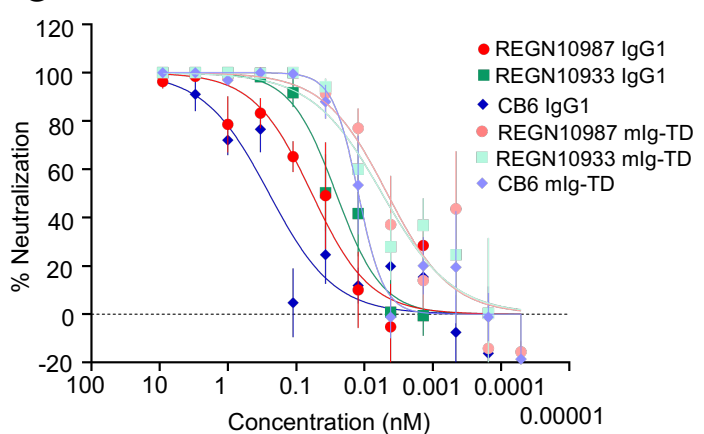

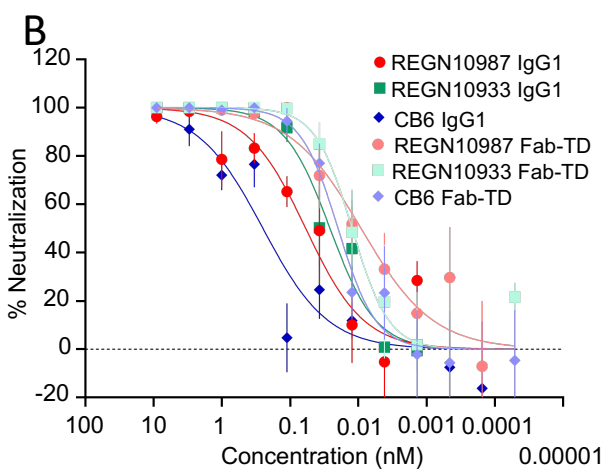

D

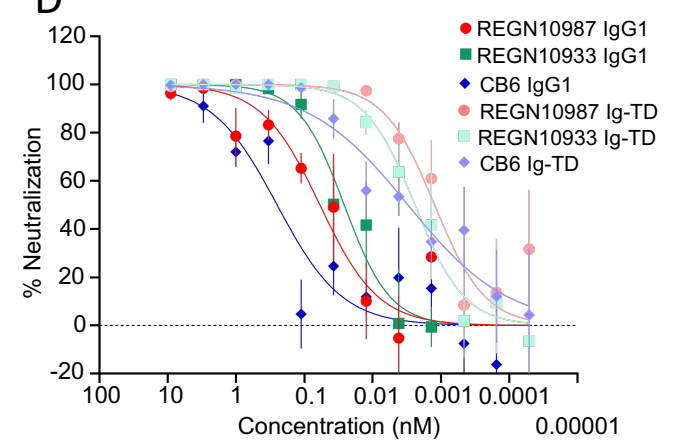

E

\begin{tabular}{|l|c|c|c|}
\hline \multicolumn{1}{|c|}{ Antibody } & $\begin{array}{c}\text { PV assay: } \\
\text { IC }\end{array}$ & $\begin{array}{c}\text { PV assay: } \\
\text { fold change compared } \\
\text { to IgG }\end{array}$ & $\begin{array}{c}\text { PV assay: } \\
\mathrm{IC}_{50}(\mu \mathrm{g} / \mathrm{mL})\end{array}$ \\
\hline REGN10987 IgG1 & 0.059 & & 0.008502 \\
\hline REGN10987 Fab-TD & 0.009 & 7 & 0.001903 \\
\hline REGN10987 mlg-TD & 0.005 & 12 & 0.001566 \\
\hline REGN10987 Ig-TD & 0.001 & 59 & 0.000308 \\
\hline & & & 0.003775 \\
\hline REGN10933 IgG1 & 0.026 & & 0.002562 \\
\hline REGN10933 Fab-TD & 0.012 & 2 & 0.001892 \\
\hline REGN10933 mIg-TD & 0.006 & 4 & \\
\hline REGN10933 Ig-TD & 0.002 & 13 & 0.00062 \\
\hline & & & 0.004272 \\
\hline CB6/Junshi IgG1 & 0.249 & & 0.003785 \\
\hline CB6/Junshi Fab-TD & 0.020 & 12 & \\
\hline CB6/Junshi mlg-TD & 0.012 & 21 & 0.000931 \\
\hline CB6/Junshi Ig-TD & 0.003 & 83 & \\
\hline & & & \\
\hline H4-scFv-TD & 0.039 & & \\
\hline
\end{tabular}

Figure 4. Neutralization of pseudovirus infection by tetramerized clinical stage SARS-CoV-2 antibodies

The potency of clinical stage mAbs that were engineered as tetramer formats was measured in SARS-CoV-2 pseudovirus infection assays. Increasing concentrations of 
antibodies were incubated with HEK 293T/1A2-T2 cells after 1 hour. The cells were incubated for 60 hours before luciferase activity was determined to show viral entry. The data are split to different panels for clarity. Panel A: The neutralization potency of H4-scFTD Quad was compared to clinical stage REGN10987, REGN10933 and CB6/Junshi IgG1. Panel B: The neutralization potency of REGN10987, REGN10933 and CB6/Junshi IgG1 was compared to REGN10987 Fab-TD, CB6/Junshi Fab-TD and REGN10933 FabTD. Panel C: The neutralization potency of the REGN10987, REGN10933 and CB6/Junshi IgG1 was compared to REGN10987 mlg-TD, REGN10987 mlg-TD and CB6/Junshi mlgTD. Panel D: The neutralization potency of the REGN10987, REGN10933 and CB6/Junshi IgG1 was compared to REGN10987 lg-TD, CB6/Junshi Ig-TD and REGN10933 Ig-TD. The assays were performed twice and each point in duplicate. The error bars indicate the standard errors. Computed $\mathrm{IC}_{50}$ data $(\mathrm{nM}$ and $\mu \mathrm{g} / \mathrm{ml}$ ) and fold change based on $\mathrm{nM}$ are shown in panel $\mathrm{E}$. 
A.

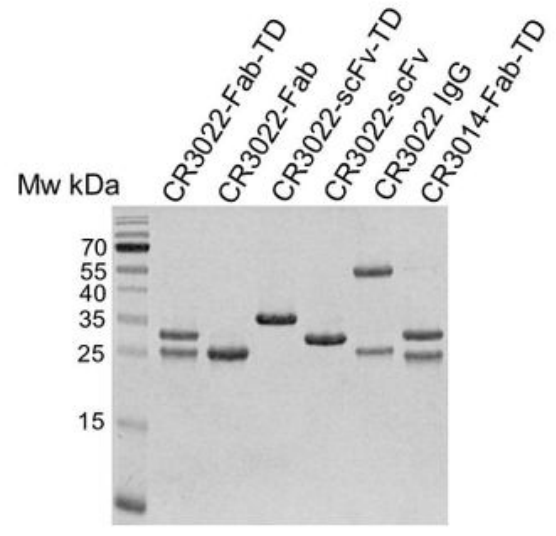

C.

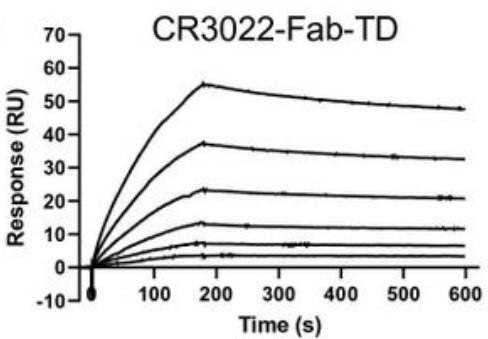

E.

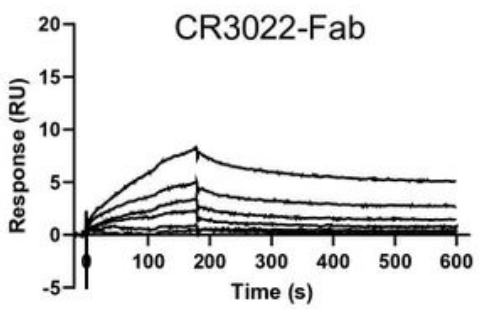

G.

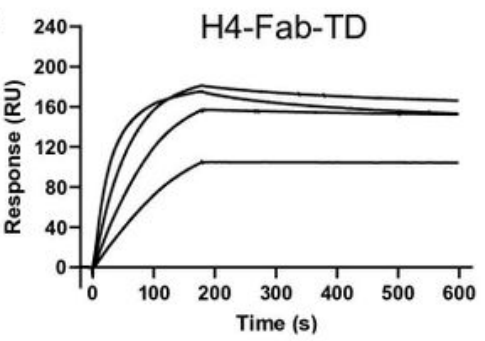

I.

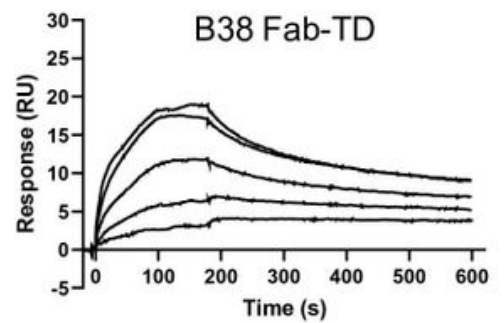

B.

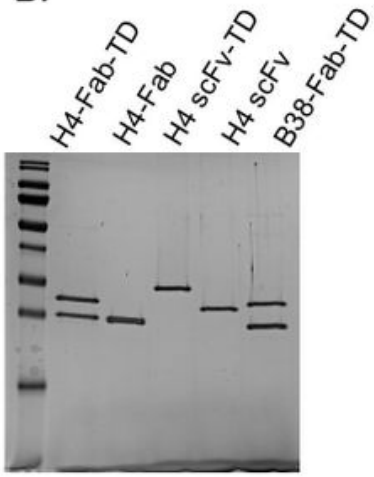

D.

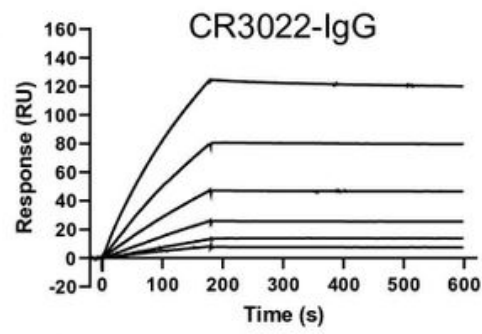

F.

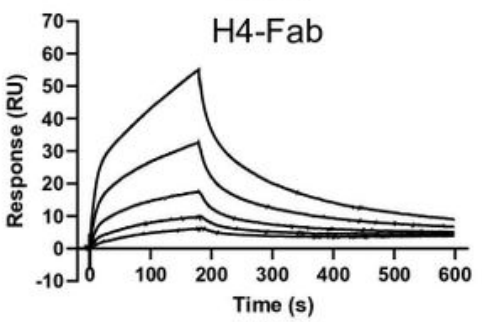

$\mathrm{H}$.

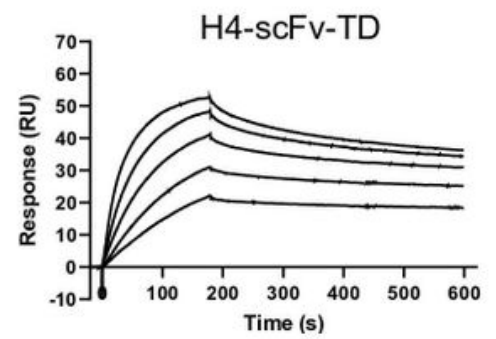

Figure 1

Characterization of anti-SARS-Cov-2 antibodies with different valencies by surface plasmon resonance The binding potencies of the anti-SARS-Cov-2 tetrameric Quad proteins was determined using surface plasmon resonance. Purified proteins were captured using immobilized SARS-Cov-2 RBD, carried out with 
a Biacore T200 instrument. (A) Anti-SARS-Cov-2 antibodies were expressed by transfection and secretion from Expi293 suspension cells and characterized by SDS-PAGE following purification by Niaffinity chromatography and gel filtration. Gels were stained with InstantBlue Ultrafast Protein Stain and Mw size markers included (left hand lanes). (C-I) Antibody binding to SARS-Cov-2 RBD was evaluated using SPR. Biotinylated SARSCoV-2 RBD was captured on a streptavidin chip and antibodies flowed over the surface at different concentrations. CR3022 and CR3014 antibody concentrations were 10, 5, 2.5, 1.25, 0.625 and $0.312 \mathrm{nM}$, while those for $\mathrm{H} 4$ and $\mathrm{B} 38$ antibodies were $12.5,6.25,3.125,1.56$ and $0.78 \mathrm{nM}$. Sensograms representative of two independent experiments are shown for (C) CR3022-Fab-TD, (D) CR3022-IgG, (E) CR3022-Fab, (F) H4-Fab (G) H4-Fab-TD (H) H4-scFv-TD and (I) B38-Fab-TD. Kinetic parameters are shown in Supplementary Table S1. Tetramerization decreases dissociation rates for the multimeric species compared to the monomeric proteins. This results in increased affinity for SARS-Cov-2 RBD for CR3022Fab-TD compared to CR3022-Fab, and for H4-Fab-TD and H4-scFv-TD compared to H4-Fab.
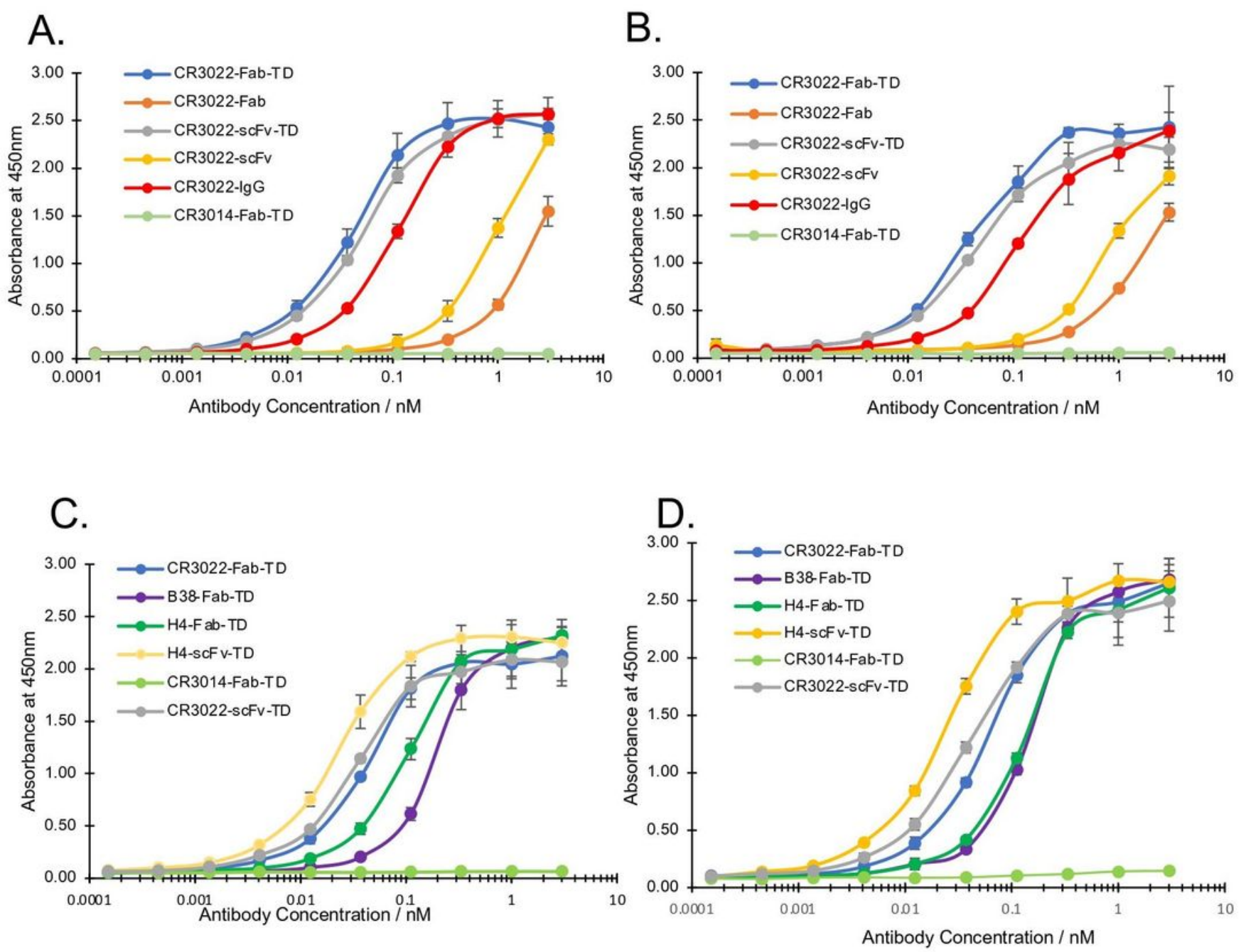

Figure 2

Direct ELISA immunoassays with anti-SARS-CoV-2 antibodies detecting viral spike proteins The ability and potency of engineered anti-SARS-CoV-2 antibodies to bind to the viral spike proteins was compared 
using Enzyme-linked immunosorbent assays (ELISAs). SARS-CoV-2 spike protein as either S1 (panel A and C) or RBD (panel B and D) was adsorbed onto immunoassay plates at $2 \mu \mathrm{g}$ per $\mu \mathrm{L}$ for 16 hours at 4 $\mathrm{OC}$. Wells were thoroughly washed, blocked, and various concentrations of the indicated His-tagged antibodies were added to each well and incubated for 16 hours at 40C, followed by washing and incubation with anti-His-HRP antibody for 2 hours at room temperature. Colour was developed using TMB and absorbance read at 450 . All samples were run in triplicate.
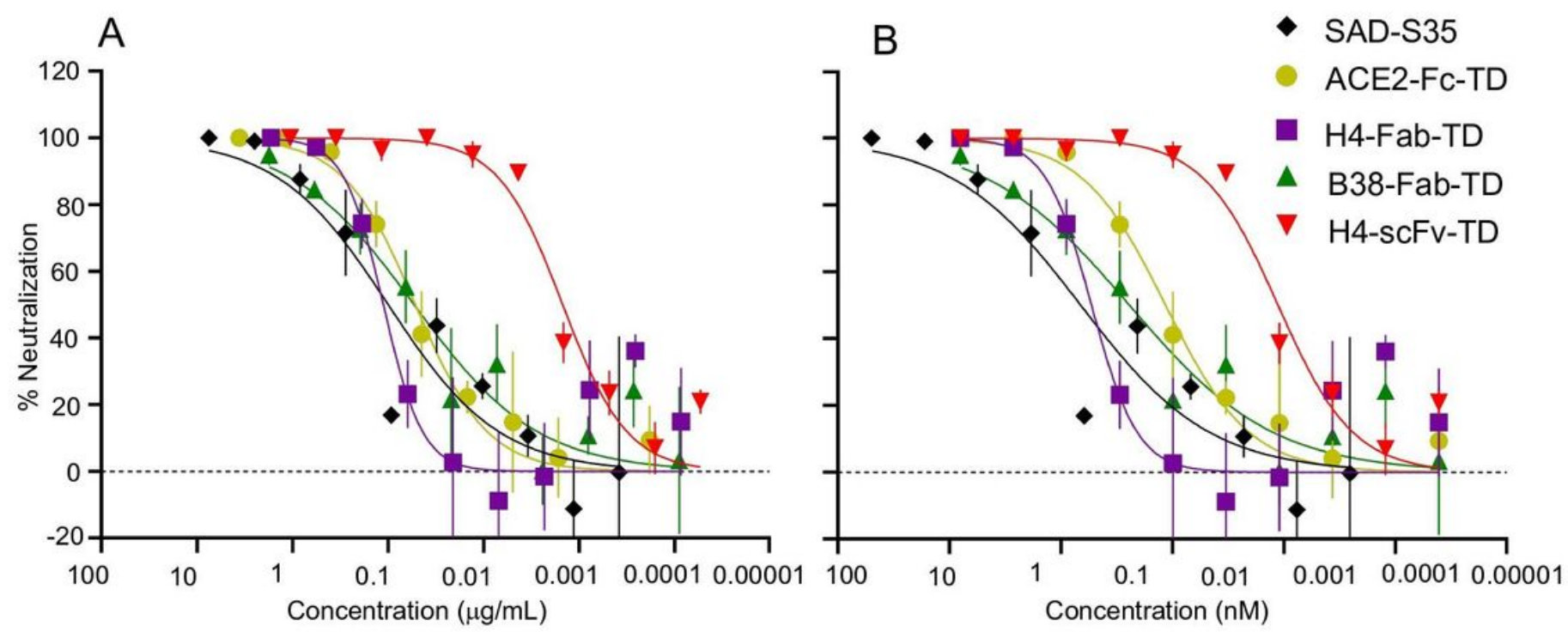

\begin{tabular}{|l|l|}
\hline Anti-CoV-2 protein & $\mathrm{IC}_{50}(\mu \mathrm{g} / \mathrm{mL})$ \\
\hline SAD-S35 & 0.099 \\
\hline ACE2-Fc-TD & 0.052 \\
\hline B38-Fab-TD & 0.112 \\
\hline H4-Fab-TD & 0.053 \\
\hline H4-ScFv-TD & 0.001 \\
\hline
\end{tabular}

\begin{tabular}{|l|l|}
\hline Anti-CoV-2 protein & IC $_{50}(\mathbf{n M})$ \\
\hline SAD-S35 & 0.663 \\
\hline ACE2-Fc-TD & 0.115 \\
\hline B38-Fab-TD & 0.531 \\
\hline H4-Fab-TD & 0.243 \\
\hline H4-scFv-TD & 0.011 \\
\hline
\end{tabular}

\section{Figure 3}

Tetramerized $\mathrm{H} 4$ and B38 anti-SARS-CoV-2 antibodies are potent inhibitors of virus infection The viral infection neutralizing potency of tetrameric versions of the mAbs H4 and B38 was examined in SARSCoV-2 pseudovirus infection assays. Increasing concentrations of H4-scFv-TD, H4-Fab-TD or B38-Fab-TD were incubated with HEK 293T/17-A2-T2 cells after 1 hour. The cells were incubated for 60 hours before luciferase activity, indicative of viral entry, was determined. The efficacy was compared to the neutralization effects of a commercial anti-SARS-CoV-2 mAb SAD-S35 (AcroBiosystems) and a tetramerized ACE2-Fc-TD. Data are represented in $\mu \mathrm{g} / \mathrm{mL}$ (panel A) and $\mathrm{nM}$ (panel B). Calculated IC50 values are tabulated below each set of curves. The assays were performed twice, in duplicate with error bars indicating the standard error. 

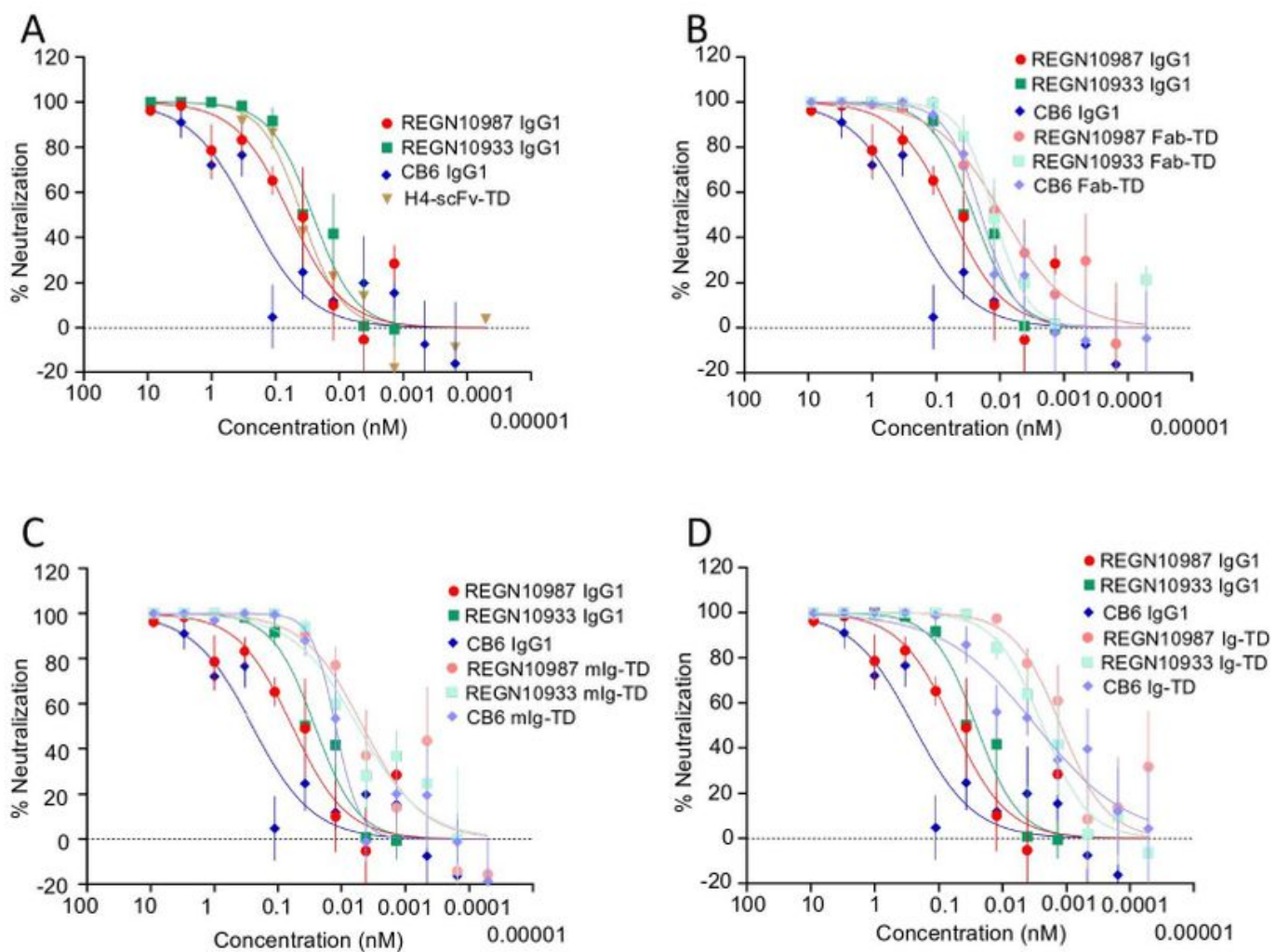

\begin{tabular}{|c|c|c|c|}
\hline Antibody & $\begin{array}{l}\text { PV assay: } \\
I_{50}(\mathrm{nM})\end{array}$ & $\begin{array}{c}\text { PV assay: } \\
\text { fold change compared } \\
\text { to IgG }\end{array}$ & $\begin{array}{l}\text { PV assay: } \\
\mathrm{IC}_{50}(\mu \mathrm{g} / \mathrm{mL})\end{array}$ \\
\hline REGN10987 IgG1 & 0.059 & & 0.008502 \\
\hline REGN10987 Fab-TD & 0.009 & 7 & 0.001903 \\
\hline REGN10987 mlg-TD & 0.005 & 12 & 0.001566 \\
\hline REGN10987 Ig-TD & 0.001 & 59 & 0.000308 \\
\hline REGN10933 IgG1 & 0.026 & & 0.003775 \\
\hline REGN10933 Fab-TD & 0.012 & 2 & 0.002562 \\
\hline REGN10933 mlg-TD & 0.006 & 4 & 0.001892 \\
\hline REGN10933 lg-TD & 0.002 & 13 & 0.00062 \\
\hline CB6/Junshi IgG1 & 0.249 & & 0.036155 \\
\hline CB6/Junshi Fab-TD & 0.020 & 12 & 0.004272 \\
\hline CB6/Junshi mlg-TD & 0.012 & 21 & 0.003785 \\
\hline CB6/Junshi Ig-TD & 0.003 & 83 & 0.000931 \\
\hline H4-scFv-TD & 0.039 & & 0.005148 \\
\hline
\end{tabular}

\section{Figure 4}

Neutralization of pseudovirus infection by tetramerized clinical stage SARS-CoV-2 antibodies The potency of clinical stage mAbs that were engineered as tetramer formats was measured in SARS-CoV-2 pseudovirus infection assays. Increasing concentrations of antibodies were incubated with HEK 293T/1A2-T2 cells after 1 hour. The cells were incubated for 60 hours before luciferase activity was determined to show viral entry. The data are split to different panels for clarity. Panel A: The 
neutralization potency of H4-scFTD Quad was compared to clinical stage REGN10987, REGN10933 and CB6/Junshi IgG1. Panel B: The neutralization potency of REGN10987, REGN10933 and CB6/Junshi IgG1 was compared to REGN10987 Fab-TD, CB6/Junshi Fab-TD and REGN10933 FabTD. Panel C: The neutralization potency of the REGN10987, REGN10933 and CB6/Junshi IgG1 was compared to REGN10987 mlg-TD, REGN10987 mlg-TD and CB6/Junshi mlgTD. Panel D: The neutralization potency of the REGN10987, REGN10933 and CB6/Junshi IgG1 was compared to REGN10987 lg-TD, CB6/Junshi IgTD and REGN10933 lg-TD. The assays were performed twice and each point in duplicate. The error bars indicate the standard errors. Computed IC50 data ( $\mathrm{nM}$ and $\mu \mathrm{g} / \mathrm{ml}$ ) and fold change based on $\mathrm{nM}$ are shown in panel $\mathrm{E}$.

\section{Supplementary Files}

This is a list of supplementary files associated with this preprint. Click to download.

- Supplementaryinformationcombinedtitlev12.pdf 